IZA DP No. 1086

Wage Mobility: Do Institutions Make a Difference? A Replication Study Comparing Portugal and the UK

Ana Rute Cardoso

March 2004 


\title{
Wage Mobility: Do Institutions Make a Difference? A Replication Study Comparing Portugal and the UK
}

\author{
Ana Rute Cardoso \\ IZA Bonn, \\ Universidade de Minho and CEPR
}
Discussion Paper No. 1086
March 2004

\author{
IZA \\ P.O. Box 7240 \\ 53072 Bonn \\ Germany \\ Phone: +49-228-3894-0 \\ Fax: +49-228-3894-180 \\ Email: iza@iza.org
}

\begin{abstract}
Any opinions expressed here are those of the author(s) and not those of the institute. Research disseminated by IZA may include views on policy, but the institute itself takes no institutional policy positions.

The Institute for the Study of Labor (IZA) in Bonn is a local and virtual international research center and a place of communication between science, politics and business. IZA is an independent nonprofit company supported by Deutsche Post World Net. The center is associated with the University of Bonn and offers a stimulating research environment through its research networks, research support, and visitors and doctoral programs. IZA engages in (i) original and internationally competitive research in all fields of labor economics, (ii) development of policy concepts, and (iii) dissemination of research results and concepts to the interested public.
\end{abstract}

IZA Discussion Papers often represent preliminary work and are circulated to encourage discussion. Citation of such a paper should account for its provisional character. A revised version may be available on the IZA website (www.iza.org) or directly from the author. 
IZA Discussion Paper No. 1086

March 2004

\section{ABSTRACT}

\section{Wage Mobility: Do Institutions Make a Difference? A Replication Study Comparing Portugal and the UK*}

This study compares wage mobility in Portugal and the UK, replicating the work by Dickens (2000) and progressing to discuss the impact of differences in the institutional framework, which is more regulated and centralized in Portugal, with minimum wages, employment protection, and collective bargaining widely applied. Results indicate that both countries became more unequal and less mobile labour markets, having departed from similar levels in mid-80s. The evidence does not support the idea that a more regulated institutional framework reduces individual mobility within the wage distribution.

JEL Classification: J31, J60

Keywords: wage mobility, wage dispersion

Ana Rute Cardoso

IZA

P.O.Box 7240

53072 Bonn

Germany

Tel.: +492283894508

Fax: +492283894 180

E-mail: cardoso@iza.org

Funding from the Bank of Portugal and Fundação para a Ciência e a Tecnologia (contract $\mathrm{POCTI/ECO/37668/2001)}$ is acknowledged. I am grateful to the Ministry of Employment, Statistics Department, for access to the data set. The usual disclaimer applies. 


\section{Introduction}

In recent years, wage mobility has been subject to growing interest, mainly driven by the search for policy responses to the widespread increase in labour market inequality. Indeed, in particular in the UK and the USA, the relative position of low-paid workers has worsened markedly, as their wages deteriorated either in absolute terms or relative to the rest of the economy. If this rise in wage inequality were accompanied by an increase in wage mobility, a specific position in the wage distribution would have become a more temporary situation in a worker's life cycle, with ample opportunity for his/her fortune to change over time. In particular, low wages could, in that case, be an entry gate into employment. On the contrary, if mobility were declining, positions in the wage hierarchy would have become more persistent, and in particular the low-paid would be trapped to remain in a situation of deteriorating wages over their life cycle, eventually revolving between low-pay, unemployment and welfare recipiency, a situation deserving more concern, from a welfare and Social Security point of view. The implications of rising wage dispersion therefore depend crucially on whether it reflects transitory fluctuations in earnings, or an increase in permanent differences across workers.

Even though the literature on the UK and the USA has focused mainly on mobility out of low-wages, the issue is also relevant at higher wage levels. For example, the incentives for acquisition of human capital depend, not just on the returns to that investment (reflected in the dispersion of the wage distribution), but also on its risk (reflected in the probability of upward and downward mobility).

In Portugal, wage dispersion increased sharply during the 'eighties and the first half of the 'nineties, but no evidence has so far been gathered on wage mobility. A comparison with the UK could provide interesting insights, checking whether the common trends concerning wage inequality also applied to wage mobility, despite the contrasts in labour market institutions. Indeed, the British labour market is recognized as a very flexible one in Europe, whereas Portugal presents a more regulated framework and a more centralized wage bargaining system, which could 
lead to lower wage mobility. In fact, collective bargaining sets wages for detailed categories of workers, defining specific wage hierarchies. Since the extension of contracts to non-unionized workers is widespread, most of the workforce is covered by collective bargaining and could therefore be subject to a rigid wage hierarchy.

The aim of this study is therefore to add comparable cross-country evidence on earnings mobility, discussing the impact of institutional differences in the labour market. Results on Portugal will be compared to those for the UK, following closely the methodology by Dickens (2000). The overlapping period with information reported for both countries is 1986-94, and the analysis on Portugal is extended to 1999. The major questions to be answered are: What is the extent of wage mobility in Portugal, and how does it compare to the UK? Is a more strongly regulated labour market more likely to protect low-wage workers, sustaining their wages, while nevertheless reducing their chances of upward mobility, and reducing overall wage mobility in the economy? How has wage mobility evolved over time in a country marked by sharp growth rates during the second half of the 1980s and by severe shortage of skills? Has it shared the decline in mobility that has taken place in the UK? Which institutional forces can drive the similarities and differences between the UK and Portugal, concerning patterns, levels and trends in wage mobility?

The study relies on a remarkable longitudinal matched employer-employee data set, covering all the wage-earners in manufacturing and services private sector in Portugal. Problems commonly faced by panel data sets, such as under- or oversampling of certain groups, and panel attrition, are thus reduced. Also, the legal requirement for the data to be posted in the company contributes to its reliability, reducing measurement errors.

Section 2 provides details on the data source and concepts used. Section 3 overviews trends in wage dispersion. Section 4 detects patterns in wage mobility, comparing groups of workers with different wage levels, and over different time horizons. The evolution of short-term wage mobility is then analyzed in section 5 and section 6 deals with trends in longer-term wage mobility. Section 7 discusses 
some of the institutional forces that may have driven the similarities and contrasts identified between the UK and Portugal, before concluding comments are presented in the final section.

\section{Data source and concepts used}

\subsection{Data set}

A longitudinal data set matching firms and workers in the Portuguese economy, is used. The data are gathered annually by the Ministry of Employment, based on an inquiry that every establishment with wage-earners is legally obliged to fill in. Reported data cover all the personnel working for the establishment in a reference week (in March until 1993, and in October from 1994 onwards). Public administration and domestic service are not covered, whereas the coverage of agriculture is low, given its low share of wage-earners. For the remaining sectors, the mandatory nature of the survey leads to an extremely high response rate, and in fact the population of firms with wage-earners in manufacturing and the services private sector is covered.

Reported data on the worker include the gender, age, schooling, monthly earnings (split into several components) and duration of work. A worker identification code, based on a transformation of the social security number, enables tracking him/her over time. The panel data set built covers the period 1986 to $1999^{1}$. Extensive checks have been performed to guarantee the accuracy of the data, using the variables gender, date of birth and highest schooling level achieved, according to the steps described in detail in the appendix. The final panel includes over 22 million observations worker-year and almost 5 million workers.

\subsection{Population under analysis}

Following Dickens (2000), the analysis is carried out separately for males and females, and it focuses on workers aged 22 to 59 . Table 1 reports, for each year, the number of workers included in the panel. For consistency with Dickens (2000),

\footnotetext{
${ }^{1}$ Note, however, that no worker data were reported for the year 1990.
} 
reported workers with missing wage (because they are not wage-earners, but instead owners of the company, unpaid family members or members of cooperatives, according to the Portuguese classification) were kept in the analysis of transition matrices.

\begin{tabular}{|c||c|c|c|c|}
\hline \multicolumn{1}{|c||}{} & \multicolumn{2}{c|}{ Males } & \multicolumn{2}{c|}{ Females } \\
\hline year & wage-earner & missing wage & wage-earner & missing wage \\
\hline \hline 1986 & 679,751 & 94,104 & 335,062 & 46,326 \\
1987 & 683,846 & 95,309 & 342,133 & 49,679 \\
1988 & 708,288 & 103,053 & 367,786 & 51,077 \\
1989 & 756,500 & 113,269 & 410,058 & 55,870 \\
1991 & 789,935 & 120,915 & 458,624 & 66,022 \\
1992 & 806,977 & 123,114 & 484,945 & 70,295 \\
1993 & 803,051 & 119,113 & 494,921 & 65,267 \\
1994 & 811,444 & 119,254 & 535,842 & 64,823 \\
1995 & 838,239 & 122,020 & 565,767 & 68,450 \\
1996 & 838,151 & 122,158 & 579,290 & 70,031 \\
1997 & 887,284 & 112,836 & 631,229 & 60,997 \\
1998 & 909,893 & 119,717 & 655,933 & 70,610 \\
1999 & 950,549 & 127,396 & 702,173 & 77,474 \\
\hline
\end{tabular}

Table 1: Size of THE DATA SET Under ANALYSis.

Source: Computations based on Portugal, MTSS (1986-1999). Note: Workers who are not wage-earners (but instead owners of the company, unpaid family members or members of cooperatives) were assigned missing wages.

Data on unemployed workers is not available on the Portuguese data set. Therefore, once a worker drops out of the data base, one of several situations may have occurred: (s)he may have become unemployed, inactive, or an independent worker, may have joined an uncovered sector (Public Administration) or the Army. Even though unemployment is the most likely situation, when analyzing transition matrices, the cell unemployed must be replaced with out of the data base, and caution exerted in comparing the results between the UK and Portugal.

\subsection{Wage concept}

Gross actual hourly earnings were computed as

$$
h w=\frac{b w+\text { sen }+ \text { reg }+ \text { overt } w}{\text { normh }+ \text { overth }},
$$

where $b w$ stands for base-wage, sen are seniority-indexed components of pay, reg are other regularly paid components and overtw is payment for overtime; normh 
refers to the normal duration of work and overth are overtime hours.

\section{Trends in wage dispersion}

Figure 1 reports the Gini index for gross hourly earnings in Portugal and the UK, computed in either case from employer reported worker level data. Comparison between the two countries can be performed after 1985, even though data for the UK are available for a wider period.
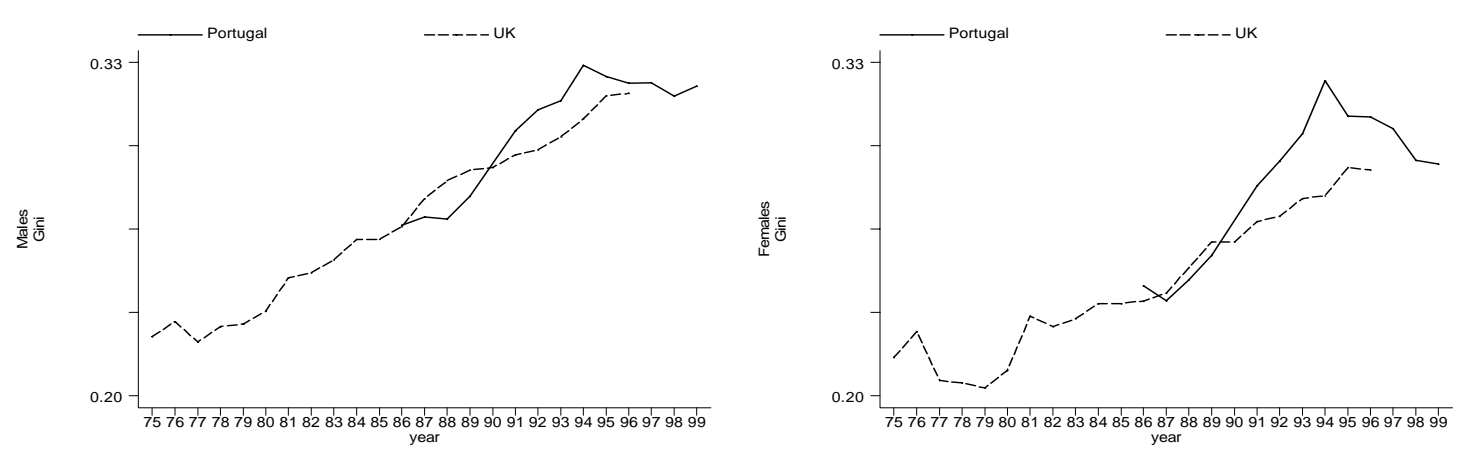

Figure 1: Trends in Wage Dispersion, Portugal and the UK.

Source: For Portugal - Computations based on Portugal, MTSS (1986-1999); for the UK - Machin (1998). Note: For Portugal, workers aged 22 to 59; no age limits are mentioned for the UK. The values for Portugal in 1990 result from linear extrapolation of the trend, since no worker data are available.

The similarity between the level of wage dispersion in Portugal and the UK in 1986 is outstanding. ${ }^{2}$ Moreover, in both countries inequality increased very sharply until mid-90s. However, in Portugal it increased at a faster pace up to 1994, but declined afterwards, whereas in the UK it kept increasing.

Figure 2 considers separately dispersion at the bottom and at the top halves of the distribution. It reports the ratios between the percentiles 50/10 and 90/50. The contrast between the pattern of wage dispersion in the UK and Portugal is striking. The bottom part of the distribution is much more compressed in Portugal, whereas, conversely, the top is much more stretched. Similar levels of overall wage dispersion therefore result from a very different pattern, with a compressed bottom and a stretched top in Portugal. The compression at the bottom reflects

\footnotetext{
${ }^{2}$ Using data from the Family Expenditure Survey, instead of the New Earnings Survey, both reported in Machin (1998), indicates a similar level of wage dispersion in Portugal and the UK in 1994, with lower departing values in Portugal in 1986 and a much faster increase in inequality during that period, specially among women.
} 
the impact of the national minimum wage, pulling low-wages closer to the middle of the distribution. ${ }^{3}$ The wider dispersion at the bottom in the UK is a major reason justifying why concern with declining wage mobility has focused so much on its implications for low-wage workers.
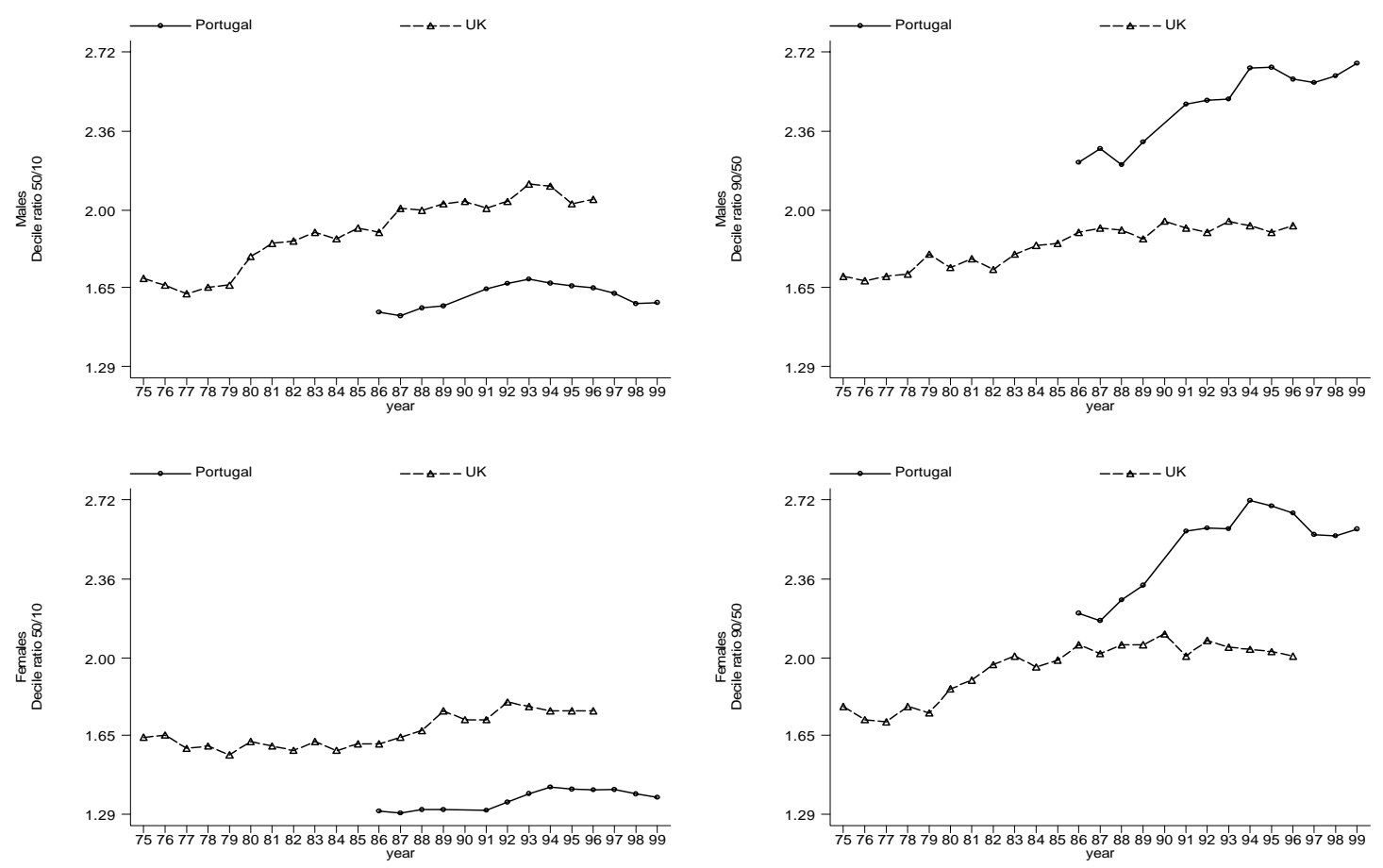

Figure 2: Trends in WAge Dispersion at the bottom AND top of the Distributions, PorTugAL AND THE UK.

Source: for Portugal - computations based on Portugal, MTSS (1986-1999); for the UK - Machin (1998). Note: For Portugal, workers aged 22 to 59; no age limits are mentioned for the UK.

\section{Patterns of wage mobility using transition matrices}

To compare the level of mobility over different time horizons, Dickens focused on the following time spans: 1993-94 (one-year), 1991-94 (three-year) and 198994 (five-year). When choosing the time spans under analysis for Portugal, two constraints should be kept in mind: in 1994, the reference week for the inquiry changed from March to October, and therefore 1993-94 captures changes over a

\footnotetext{
${ }^{3}$ In the UK, the national minimum wage was introduced in 1999, and its impact is therefore beyond the time frame of the data presented.
} 
longer period (19 months), rendering it infeasible for comparison with the remaining periods; in 1990, no worker data were reported. Given these constraints, to compare levels of mobility over different time horizons, the following time spans will be analyzed for Portugal: 1991-92 (one-year), 1989-92 (three-year) and 198792 (five-year), thus sliding backwards Dickens's windows by two years.

\subsection{Mobility by wage group}

Mobility patterns in the Portuguese labour market are very similar to those that have been detected by Dickens for the UK. First of all, the mobility matrix in table 2 reports for males a high degree of earnings persistence, with the proportion of workers who does not change decile ranging from 31 percent to 66 percent, depending on the decile of origin. Most of those who travel in the wage distribution, do so for a short distance. Immobility is apparently higher for the lower and upper tails of the distribution, a pattern found, not just for the UK, but also for Germany and the USA (Burkhauser et al, 1997). It should nevertheless be noted that part of the immobility detected for the tails of the distribution results from the methodology used. Due to the shape of the earnings distribution, the upper decile covers a wider range of wages, and therefore it would take a larger wage variation to move the worker into a different decile; also, at either end of the distribution, there is less room to escape, as workers are bound to move only in one direction.

Secondly, similar to the UK, the lowest paid workers are more likely to end up, the following year, in a situation of unemployment. ${ }^{4}$ Likewise, those that were unemployed/out of the data base, are more likely to enter employment with low wages.

All of these patterns hold for females as well, even though persistence in the lowest decile is not as high, just like in the UK, with one fourth of the women moving up the wage distribution over the period of one year in Portugal.

\footnotetext{
${ }^{4}$ More rigorously, out of the data base in Portugal.
} 


\begin{tabular}{|r||c|c|c|c|c|c|c|c|c|c|c|c|}
\hline \multicolumn{1}{|c||}{} & \multicolumn{10}{c|}{ State in 92 } \\
\hline State in 91 & out db* & miss w* & 1 & 2 & 3 & 4 & 5 & 6 & 7 & 8 & 9 & 10 \\
\hline out db* $^{*}$ & & 16.1 & 13.9 & 11.7 & 10.7 & 9.7 & 8.5 & 7.7 & 6.2 & 5.4 & 4.8 & 5.3 \\
miss w & 32.4 & 47.6 & 2.3 & 2.0 & 2.0 & 2.0 & 2.1 & 1.9 & 1.8 & 1.8 & 2.2 & 2.1 \\
1 & 32.8 & 4.4 & 41.4 & 12.0 & 3.7 & 2.0 & 1.2 & 0.8 & 0.5 & 0.3 & 0.3 & 0.8 \\
2 & 29.2 & 3.9 & 10.4 & 33.7 & 12.8 & 4.6 & 2.3 & 1.3 & 0.8 & 0.4 & 0.3 & 0.5 \\
3 & 27.4 & 3.7 & 2.1 & 12.4 & 31.1 & 13.8 & 4.8 & 2.1 & 1.1 & 0.7 & 0.4 & 0.5 \\
4 & 25.6 & 3.5 & 1.1 & 3.0 & 13.4 & 31.2 & 14.2 & 4.4 & 1.7 & 0.9 & 0.5 & 0.6 \\
5 & 22.9 & 3.6 & 0.7 & 1.4 & 3.6 & 13.5 & 33.7 & 14.1 & 3.6 & 1.4 & 0.7 & 0.6 \\
6 & 20.8 & 3.5 & 0.5 & 0.8 & 1.4 & 2.9 & 13.1 & 37.5 & 14.0 & 3.6 & 1.2 & 0.7 \\
7 & 17.7 & 3.5 & 0.4 & 0.5 & 0.7 & 1.1 & 2.6 & 12.7 & 43.0 & 13.9 & 3.0 & 1.1 \\
8 & 15.4 & 3.3 & 0.2 & 0.3 & 0.5 & 0.7 & 0.9 & 2.4 & 13.4 & 47.9 & 12.7 & 2.3 \\
9 & 14.0 & 2.7 & 0.2 & 0.2 & 0.2 & 0.4 & 0.5 & 0.9 & 2.0 & 12.7 & 55.3 & 10.9 \\
10 & 15.1 & 3.5 & 0.5 & 0.4 & 0.4 & 0.5 & 0.6 & 0.6 & 0.9 & 1.8 & 10.4 & 65.3 \\
\hline
\end{tabular}

Table 2: Transition matrix, males, Portugal, 1991-92.

Source: Computations based on Portugal, MTSS (1991-1992). Notes: $\left(^{*}\right)$ out db - out of the database; miss w - missing wage (workers who are not wage-earners, but instead owners of the company, unpaid family members or members of cooperatives).

\subsection{Mobility over different time horizons}

Over longer time horizons, the opportunities for wage variation —and therefore for workers to swap positions in the wage distribution — are higher. So, mobility over a three-year period is higher than over one year, and it is still higher over a five-year period (see tables 6 to 9 in appendix). This pattern of increasing mobility over longer time periods is expectable, and it holds for several countries, for example Germany and the USA (Burkhauser et al, 1997) or Austria (Hofer and Weber, 2002), besides the UK (Dickens, 2000).

Mobility patterns have been compared between the UK and Portugal using transition matrices. However, comparison of mobility levels across countries would be inaccurate, due to the different definition of the cell unemployed in the UK and out of the data base in Portugal. Moreover, it has been widely acknowledged that cross-country comparisons of levels of wage mobility are hard to perform, since the ranking of countries is highly sensitive to the (inequality) measure used (see for example OECD (1997) or Hofer and Weber (2002) $)^{5}$. Exactly the same approach should thus be used for both countries.

\footnotetext{
${ }^{5}$ Their approach follows Shorrocks (1978), to measure mobility as the extent to which an inequality index is reduced when wages are averaged over a longer time horizon.
} 


\begin{tabular}{|r||c|c|c|c|c|c|c|c|c|c|c|c|}
\hline \multicolumn{1}{|c||}{} & \multicolumn{10}{c|}{ State in 92 } \\
\hline State in 91 & out db* & miss w* & 1 & 2 & 3 & 4 & 5 & 6 & 7 & 8 & 9 & 10 \\
\hline out db* $^{*}$ & & 13.2 & 13.5 & 10.3 & 9.5 & 8.8 & 8.7 & 8.7 & 7.9 & 7.6 & 6.2 & 5.7 \\
miss w & 34.0 & 37.1 & 3.2 & 3.0 & 3.2 & 3.0 & 3.0 & 2.9 & 3.1 & 2.7 & 2.4 & 2.5 \\
1 & 33.9 & 6.5 & 33.2 & 11.7 & 5.8 & 2.8 & 2.3 & 1.4 & 1.0 & 0.6 & 0.3 & 0.6 \\
2 & 29.7 & 6.0 & 10.5 & 30.4 & 11.6 & 5.4 & 2.9 & 1.5 & 0.8 & 0.5 & 0.2 & 0.6 \\
3 & 26.2 & 6.1 & 4.4 & 11.4 & 27.5 & 13.8 & 5.7 & 2.6 & 1.0 & 0.5 & 0.3 & 0.5 \\
4 & 24.9 & 5.9 & 1.5 & 5.7 & 13.3 & 28.8 & 12.2 & 4.5 & 1.6 & 0.8 & 0.4 & 0.5 \\
5 & 24.1 & 5.6 & 1.3 & 2.4 & 5.8 & 13.0 & 29.7 & 12.0 & 3.6 & 1.3 & 0.6 & 0.6 \\
6 & 24.1 & 5.3 & 0.9 & 1.2 & 1.7 & 4.0 & 13.2 & 32.5 & 12.6 & 3.0 & 0.8 & 0.7 \\
7 & 22.9 & 5.0 & 0.6 & 0.5 & 0.8 & 1.0 & 2.6 & 13.2 & 38.6 & 12.2 & 2.0 & 0.8 \\
8 & 21.4 & 4.9 & 0.4 & 0.3 & 0.4 & 0.5 & 0.8 & 2.0 & 12.1 & 45.3 & 10.3 & 1.6 \\
9 & 18.1 & 4.1 & 0.3 & 0.1 & 0.2 & 0.2 & 0.4 & 0.6 & 1.3 & 9.1 & 56.4 & 9.1 \\
10 & 15.9 & 3.5 & 0.5 & 0.3 & 0.4 & 0.4 & 0.5 & 0.5 & 0.6 & 1.2 & 9.2 & 67.0 \\
\hline
\end{tabular}

Table 3: Transition matrix, females, Portugal, 1991-92.

Source: Computations based on Portugal, MTSS (1991-1992). Notes: $\left(^{*}\right)$ out db - out of the database; miss w - missing wage (workers who are not wage-earners, but instead owners of the company, unpaid family members or members of cooperatives).

\section{A more complete picture: trends in wage mobility based on individual ranks in the distribution}

To check changes in wage mobility over time and make comparisons of both levels and trends across countries, a synthesis measure M will be used (Dickens, 2000) ${ }^{6}$ :

$$
M=\frac{2 \sum_{i=1}^{N}\left|r a n k_{i t}-r a n k_{i s}\right|}{N}
$$

where the subscripts $t$ and $s$ refer to the year and $N$ refers to the total number of workers. $M$ is twice the average absolute jump in rank (percentile), and it ranges between 0 (no mobility) and 1 (maximum mobility). It is computed over workers who are wage-earners in both periods under analysis, therefore overcoming the limitation of having a cell that has a different meaning in the transition matrices previously reported.

\footnotetext{
${ }^{6}$ Since wages tend to rise over the life cycle, in Dickens (2000) part of the analysis of mobility is conducted removing the age effect from wages, so that actual mobility is evaluated after accounting for the life cycle trend. For comparability, the analysis from here onwards also considers age-adjusted wages, by using the residuals from a wage regression on age dummies. The patterns and trends are not affected by this change, but the mobility levels are lower.
} 


\subsection{Declining mobility}

Comparison between the UK and Portugal for the overlapping period (1987 to 1994) highlights, once again, a notable similarity — mobility levels were very similar at the start, either for males or females (see figure 3). Also, in both countries mobility has declined, for males and for females. However, the pace of decline was faster in the UK, such that by 1994 the degree of mobility was considerably lower there. It can however be noted that male wage mobility kept declining in Portugal, to reach in 1996 values almost as low as the UK two years earlier.

Concentrating on Portugal, it is noticeable that from mid-80s to late-90s wage mobility declined for males, having fluctuated sharply for females. However, within the period, different trends can be identified. Up to 1993, mobility in the male earnings distribution fluctuated around .15, whereas after 1994 it fluctuated around .13 , therefore revealing a noticeable decline at mid-90s. In the female wage distribution, the final value was slightly lower than the initial one, with a peak in 1993.
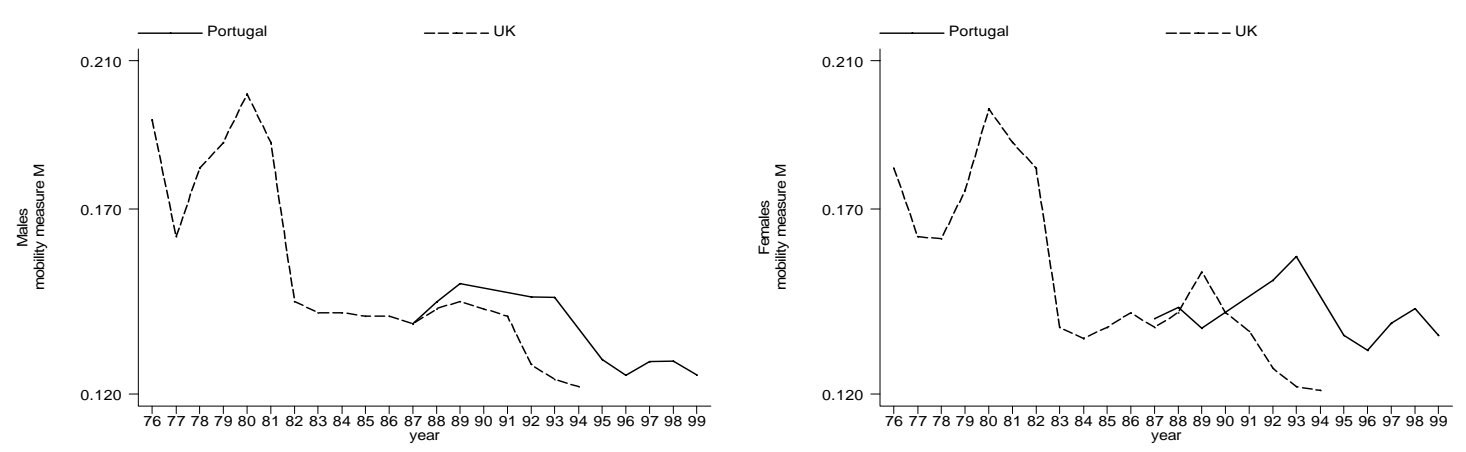

Figure 3: Trends in wage mobility, Portugal and the UK.

Source: For Portugal - Computations based on Portugal, MTSS (1986-1999); for the UK - Dickens (1997). Note: For Portugal, information for 1989-90 and 1990-91 are not available, and for 1993-94 it has not been used in the plots. Thus the values for those periods result from linear extrapolation of the trend.

A curious aspect in Portugal therefore concerns the turning point at mid-90s in the evolution of the male wage distribution. Until 1994, wage inequality was rising, and afterwards it has been declining; until 1993, mobility was high, and after 1994 it has been lower. Therefore, rising inequality was associated with relatively high 
mobility, whereas declining inequality coexisted with lower mobility. Information on a wider time horizon would be required to enable strong statements about this link between changes in inequality and the level of mobility.

Nevertheless, there is indication that the implications of rising inequality may have been different in Portugal and the UK. In the UK, there is strong evidence that rising differences among workers at a moment in time are now inflated over the life cycle, since the opportunities for positions to swap, declined (rising inequality and declining mobility throughout the period). Evidence on Portugal is less compelling. Despite the rise in inequality and the decline in mobility between the initial and final years under analysis, the evolution within that period suggests that, differently from the UK, rising inequality was accompanied by high mobility, and declining inequality was accompanied by lower mobility.

The crucial question that follows is therefore: Which workers were enjoying the higher mobility that existed in Portugal until 1993? The low-paid workers? The top wage-earners? This is the issue addressed in the next section.

\subsection{Which workers experienced higher mobility until mid-90s than af- terwards?}

Table 4 explores which groups of workers experienced gains in mobility when wage inequality was increasing. It reports the yearly mobility index $\mathrm{M}$ by decile of origin, distinguishing between the period when earnings inequality was rising and the period when it was declining. ${ }^{7}$ The last column reports the change between the two periods in the average yearly mobility index.

Over all the working population considered, the table confirms the patterns and trends previously detected: mobility is higher in the middle of the distribution while, on the contrary, higher persistence is a characteristic of the bottom and top deciles; yearly mobility in the male wage distribution was, on average, 15 percent higher until mid-90s than in the period that followed; in the female distribution, it was 8 percent higher until mid-90s.

\footnotetext{
${ }^{7}$ In 1987 , inequality was not yet increasing for females, and in 1999 it was no longer decreasing for males, so those periods were not included.
} 
It is interesting to note in table 4 a very clear pattern regarding the identification of the groups of workers who experienced much higher mobility until mid-90s than afterwards. For the half best paid group of men in the economy, mobility was until mid-90s considerably higher than afterwards (around 20 percent higher). Their earnings instability was therefore higher during that period, with a higher probability of swaps in relative positions. Note however that this did not affect the very best paid males. Indeed, those in the last decile enjoyed until mid-90s, not just a remarkable increase in their relative wages but, once that stage had been reached, considerable stability, as the mobility rates are, not just very low, but close to their post-93 levels. Males on lowest wages enjoyed, until 1993, somewhat higher mobility than afterwards (9 percent higher, for the first decile). Therefore, while the lowest wages were deteriorating relative to the rest of the male labour market, the possibility of escaping that situation was not remarkably better than after mid-90s. For women, the trend in wage mobility is more homogenous across wage deciles.

Using the period 1988-89 analysed by Dickens, one finds that overall mobility was very similar for males in the UK and Portugal (respectively 0.145 and 0.150 ), as figure 3 had already reported. Nevertheless, mobility at the tails is slightly higher in Portugal. ${ }^{8}$ The probability of escaping low wages therefore seems to be slightly higher in Portugal than in the UK, for either males or females, contrary to what a more regulated framework would lead one to expect.

Moreover, mobility declined in the UK specially for low-wage workers, a result similar to the one reported for the USA by Buchinsky and Hunt (1999). On the contrary, in Portugal, the top half best paid workers have been the ones most affected by the decline in mobility.

\section{Trends in longer-term mobility}

This section focuses on trends in longer-term mobility, over three and five years. To complement the mobility measure $\mathrm{M}$, this part of the study uses simple inspection

\footnotetext{
${ }^{8}$ Comparing table 4 with Dickens (2000: table 4 ).
} 


\begin{tabular}{|r||l|l|l||c|c|c|c||c|}
\hline \multicolumn{1}{|c|}{ MALES } & \multicolumn{2}{|c||}{ period rising inequality } & \multicolumn{3}{|c|}{ period declining inequality } & change in av. mobility \\
\hline decile origin & $88-89$ & $91-92$ & $92-93$ & $94-95$ & $95-96$ & $96-97$ & $97-98$ & between the two periods \\
\hline All & 0.150 & 0.146 & 0.146 & 0.129 & 0.125 & 0.129 & 0.129 & 1.151 \\
1 & 0.128 & 0.129 & 0.131 & 0.114 & 0.120 & 0.111 & 0.131 & 1.087 \\
2 & 0.157 & 0.151 & 0.153 & 0.132 & 0.138 & 0.138 & 0.151 & 1.098 \\
3 & 0.178 & 0.165 & 0.164 & 0.144 & 0.147 & 0.151 & 0.158 & 1.126 \\
4 & 0.186 & 0.171 & 0.168 & 0.147 & 0.149 & 0.154 & 0.157 & 1.150 \\
5 & 0.185 & 0.172 & 0.169 & 0.144 & 0.146 & 0.150 & 0.151 & $\mathbf{1 . 1 8 5}$ \\
6 & 0.175 & 0.165 & 0.164 & 0.137 & 0.135 & 0.142 & 0.140 & $\mathbf{1 . 2 1 2}$ \\
7 & 0.157 & 0.151 & 0.148 & 0.130 & 0.124 & 0.132 & 0.128 & $\mathbf{1 . 1 8 4}$ \\
8 & 0.134 & 0.135 & 0.135 & 0.116 & 0.110 & 0.115 & 0.108 & $\mathbf{1 . 1 9 7}$ \\
9 & 0.110 & 0.109 & 0.109 & 0.094 & 0.087 & 0.091 & 0.086 & $\mathbf{1 . 2 2 2}$ \\
10 & 0.088 & 0.114 & 0.122 & 0.136 & 0.094 & 0.101 & 0.079 & 1.054 \\
\hline \hline FEMALES & period rising inequality & \multicolumn{2}{|c||}{ period declining inequality } & change in av. mobility \\
\hline decile origin & $88-89$ & $91-92$ & $92-93$ & $94-95$ & $95-96$ & $96-97$ & $97-98$ & between the two periods \\
\hline All & 0.138 & 0.151 & 0.157 & 0.136 & 0.132 & 0.139 & 0.143 & 1.081 \\
1 & 0.157 & 0.169 & 0.175 & 0.152 & 0.152 & 0.149 & 0.179 & 1.058 \\
2 & 0.163 & 0.175 & 0.184 & 0.149 & 0.153 & 0.163 & 0.178 & 1.083 \\
3 & 0.161 & 0.186 & 0.198 & 0.155 & 0.157 & 0.170 & 0.183 & 1.092 \\
4 & 0.171 & 0.193 & 0.198 & 0.162 & 0.164 & 0.177 & 0.182 & 1.094 \\
5 & 0.167 & 0.183 & 0.189 & 0.152 & 0.156 & 0.166 & 0.168 & 1.119 \\
6 & 0.152 & 0.166 & 0.166 & 0.138 & 0.142 & 0.148 & 0.153 & 1.112 \\
7 & 0.135 & 0.138 & 0.143 & 0.121 & 0.127 & 0.131 & 0.130 & 1.091 \\
8 & 0.116 & 0.117 & 0.119 & 0.107 & 0.107 & 0.113 & 0.109 & 1.077 \\
9 & 0.087 & 0.083 & 0.087 & 0.087 & 0.076 & 0.079 & 0.074 & 1.084 \\
10 & 0.069 & 0.098 & 0.113 & 0.136 & 0.085 & 0.096 & 0.075 & 0.950 \\
\hline
\end{tabular}

Table 4: One-year mobility index M, By Decile of origin, Portugal.

Source: Computations based on Portugal, MTSS (1988-1998). Notes: For 1989-90 and 1990-91, mobility measures cannot be computed because no worker data are available for 1990; similarly, for 1993-94, mobility measures are not presented, because they refer to a wider time horizon, and are thus not comparable to the rest of the series. Different from Dickens (2000), no standard-errors were computed, because the data set includes the population of wage-earners in the private sector.

of an informative graphical device, which plots on the horizontal axis the rank of the worker in the wage distribution in the initial year, and on the vertical axis his/her rank in the final year. If the worker remained in the same relative position (rank), then (s)he would be represented by a dot on the diagonal of the graph. A higher concentration of points along or close to the diagonal therefore provides indication of lower mobility. Figure 4 compares mobility in the three-year periods 1988-91 and 1995-98. ${ }^{9}$ For longer-term mobility, over five years, the periods 1988-

\footnotetext{
${ }^{9}$ The requirement to compare periods with similar inflation rates is less of a constraint for Portugal than it was for the UK. In fact, Dickens highlights that, having wages at a particular point in time, the timing of wage increases is very relevant, in particular in periods of high inflation, when nominal wage adjustments will be larger, and therefore having workers whose wage has not yet been updated, together with workers whose wage has already been updated, provides a misleading idea of the true level of wage mobility. However, in Portugal, most wages are bargained over annually, with the wage change becoming effective almost invariably in January, such that the timing of wage bargaining does not undergo change depending on the inflation rate. Indeed, in periods of
} 
93 and 1993-98 are compared in figure $5 .^{10}$
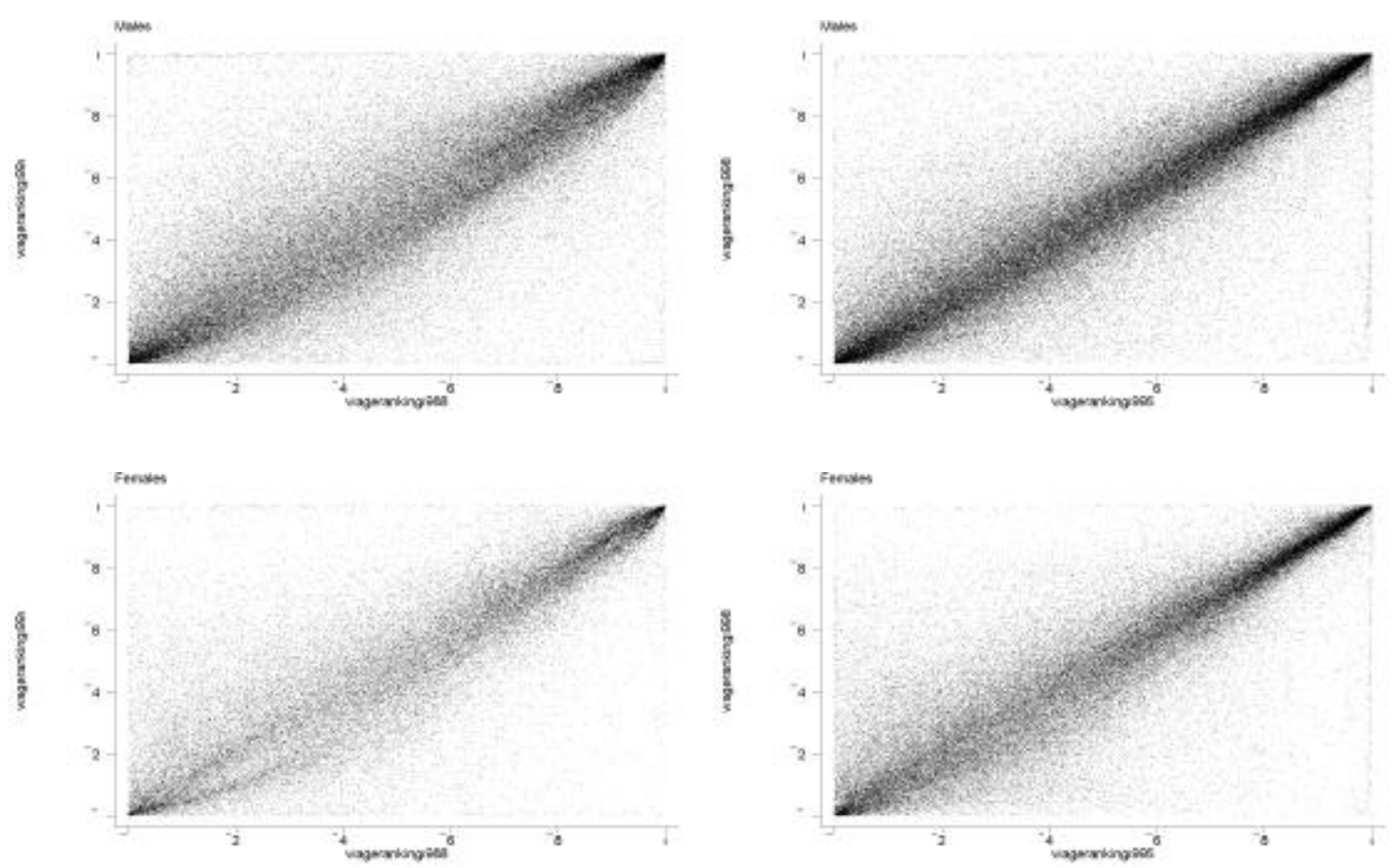

Figure 4: Three-Year mobility, males and females, Portugal.

Source: Computations based on Portugal, MTSS (1988-1998). Note: The plots refer to 25 percent samples of the data set.

It can be noted, in figure 4, that the concentration of dots along the diagonal increased from 1988-91 to 1995-98, both for males and females. Just like shortterm mobility, that over a three-year horizon also declined. The same trend holds for longer-term mobility, over five years. Thus, between mid-80s and late-90s, wage mobility declined in Portugal, irrespective of the time horizon considered (one-, three- or five-year mobility). This result is confirmed by the mobility measures reported in table 5 .

very high inflation such as the 80 s, the Government has set minimum periods for the duration of each collective agreement: from 1980 to 1989 it was imposed, as a general rule, that any collective agreement signed should last for at least two years, while its wage clauses could be updated annually; from 1989 onwards, the general rule is the annual duration of the agreements. On the other hand, all the reported data refer to the same reference week.

${ }^{10}$ Note however that the period 1993 to 1998 covers more than five years, because the inquiry took place in March 93 and October 98, therefore overstating the mobility that would have taken place over a five-year horizon. 

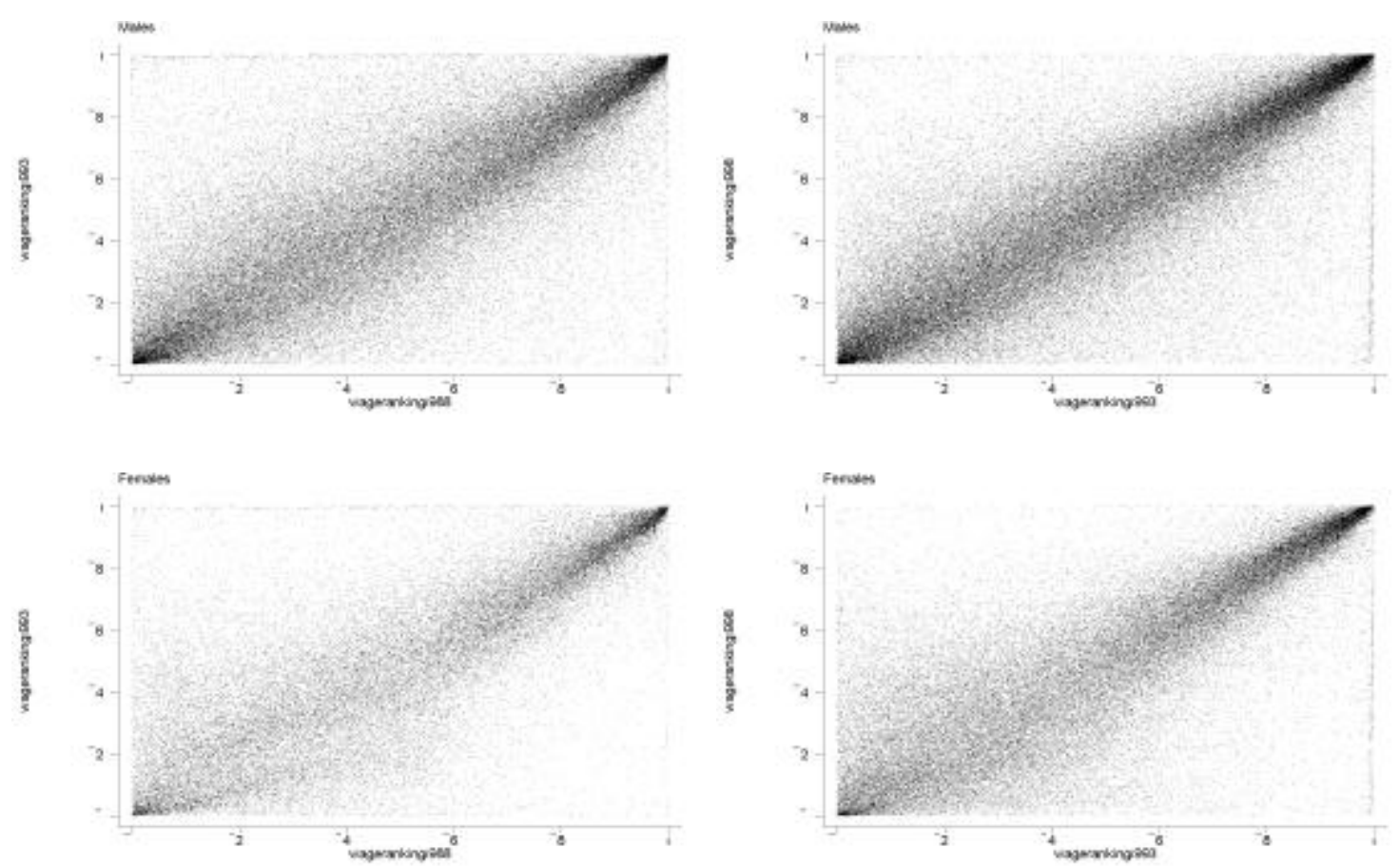

Figure 5: Five-Year mobility, males and females, Portugal.

Source: Computations based on Portugal, MTSS (1988-1998). Note: The plots refer to 25 percent samples of the data sets.

\begin{tabular}{|r||c|c||c|c|}
\hline & $1988-91$ & $1995-98$ & $1988-93$ & $1993-98$ \\
\hline Males & 0.230 & 0.179 & 0.260 & 0.231 \\
Females & 0.217 & 0.190 & 0.256 & 0.244 \\
\hline
\end{tabular}

Table 5: Mobility (index M) over three- And five-Year Periods, Males AND females, Portugal.

Source: Computations based on Portugal, MTSS (1987-1998).

\section{Discussing the impact of different institutions on labour market inequality and mobility}

Major similarities and some contrasts have been detected between the British and the Portuguese wage distributions, synthesized below, which call for discussion on underlying causes and the role played by institutional forces.

First of all, both countries became more unequal labour markets, having departed from similar levels of wage inequality in mid-80s. Secondly, both countries became less mobile labour markets, having departed from similar levels of wage 
mobility in mid-80s.

However, inequality at the bottom is striking in the UK, whereas in Portugal it is striking at the top. In other words, in the UK the poor fare worst - relative to the rest of the economy - than in Portugal. Conversely, in Portugal the rich fare better - relative to the rest of the economy - than in the UK. Also, even though mobility is, in both countries, lower at the tails of the distribution, the possibility to escape low wages is slightly higher in Portugal than in the UK. Moreover, while mobility in Portugal declined in particular for workers in the top half of the wage distribution, in the UK low-paid workers were the ones most severely hit by the decline in wage mobility.

As to the timing of the trends detected, whereas in the UK rising inequality and declining mobility seem to have been uninterrupted trends, Portugal presented in mid-90s a turning point. Until then, rising inequality was associated with high wage mobility; afterwards, declining inequality coexisted with lower wage mobility.

The minimum wage certainly had a role compressing the bottom of the wage distribution in Portugal, as it sustained the wages of less skilled workers, leading to a remarkable contrast with the UK in the pattern of wage dispersion.

On the other hand, collective bargaining might be expected to lead to a rigid wage hierarchy and low mobility in Portugal, as it defines strict wage hierarchies that are applied to both unionized and non-unionized workers. Also, stricter regulations on employment protection might be expected to lead to lower worker turnover, therefore reducing one major source of wage mobility, the transition between employers. Evidence suggests, instead, that these different institutional architectures did not lead to sharp contrasts in the level or trend of wage mobility, which were similar. Moreover, legal protection of low-wage workers does not seem to contribute to trap them in a situation of low-wage in Portugal any more than it does in the UK.

Part of the explanation may be the fact that, despite the regulated wage bargaining system, wages are in Portugal quite flexible. So does the OECD (1992) highlight, when finding that, at the macro level, wages in Portugal are among the 
most responsive to changes in the unemployment rate, and so do studies of wage adjustment at the micro level indicate. Indeed, Cardoso and Portugal (2003) found that wage adjustments by firms, beyond the levels defined by collective bargaining, provide ample scope for the firm to adapt the wage levels paid to firm- and worker-specific conditions. Similarly, Cardoso (2000) had found that firms diverge widely in the way they reward different worker attributes.

The interplay between the pace of economic change and the supply of a highly schooled labour force may also help explain some of the similarities and differences identified for the UK and Portugal. During the second half of the 1980s, growth and modernization took place at a fast pace in the Portuguese economy, and unemployment decreased from 9 percent in 1985 to 4 percent in 1991, substantially below the European Union average. This framework of growth, in an economy with a shortage of skilled labour, led to rising wage premiums for the most skilled, through rising returns to education (see Hartog et al (2001) and Cardoso (1999)). That trend was common to both countries but, in Portugal unlike in the UK, more skilled workers were precisely those whose wage mobility was higher until mid-90s than afterwards. The pace of change in the Portuguese economy during the second half of the 1980s is thus likely to provide the major clue explaining both the rising inequality, and the higher mobility existing until then for skilled workers. After mid-90s, inequality increased at a slower pace in the UK, and it decreased in Portugal. In both countries, that has been probably linked to the remarkable expansion of higher education and the rising supply of a highly educated labour force, which slowed down the pace of rising returns to education.

Evidence on other comparisons of wage mobility, such as that by Burkhauser et al (1997) on the USA and Germany, had also indicated that sharp contrasts in labour market institutions can coexist with similar patterns of wage inequality and wage mobility. Also, the OECD (1997) found that less regulation in labour and product markets, in countries such as the UK and the USA, does not result in higher levels of wage mobility. 


\section{Conclusion}

This study compared earnings mobility in the UK and Portugal. Common patterns and common trends are the major message to be highlighted from the comparison between the British and Portuguese wage distributions.

Therefore, changes in mobility levels and patterns seem to have been mainly driven by broad trends taking place in both economies, namely the interplay between modernization and technological progress, on one hand, and the supply of a highly schooled labour force, on the other, and not so much by different institutional architectures in the labour market or their change. In fact, the evidence found does not support the idea that a more regulated institutional framework in Portugal, with minimum wages, employment protection legislation and collective bargaining widely applied, reduces the degree of individual mobility within the wage the distribution.

The sharper rise in inequality during the second half of the 80s in Portugal and its slower decline in mobility are likely to be a result of the faster changes in an economy where, moreover, qualified human resources are more scarce. The period of economic growth seems to have provided opportunities for wage mobility for specific workers, holding highest skills. Much of these changes were feasible under an institutional regime that, despite apparent rigidity, leaves ample scope for firm manoeuvre when bargaining over wages.

In terms of welfare implications, it can be noted that the role played by minimum wages in Portugal, the slightly higher mobility out of low-wages, the less abrupt decline in mobility over the $80 \mathrm{~s}$ and $90 \mathrm{~s}$, and the fact that this decline in mobility affected mainly the higher-paid, render trends in this country less worrying than in the UK. It should however be kept in mind that this analysis concentrates on changes within the wage distribution in each country, and does not focus on the absolute difference in wage levels. 


\section{References}

Buchinsky, M. And Hunt, J. (1999) Wage mobility in the United States. Review of Economics and Statistics, 81(3), 351-368.

Burkhauser, R.V., Holtz-Eakin, D. and Rhody, S.E. (1997) Labor earnings mobility and inequality in the United States and Germany during the growth of thew 1980s. International Economic Review, 38(4), 775-794.

Cardoso, A.R. (1999) Firm's wage policies and the rise in labor market inequality: the case of Portugal. Industrial and Labor Relations Review, 53(1), 87-102.

Cardoso, A.R. (2000) Wage differentials across firms: an application of multilevel modelling. Journal of Applied Econometrics, 15(4), 343-354.

Cardoso, A.R. And Portugal, P. (2003) Bargained wages, wage drift and the design of the wage setting system. Mimeo.

Dickens, R. (1997) Caught in a trap? Wage mobility in Great Britain: 19751994. CEP discussion paper 365. London: Centre for Economic Performance.

Dickens, R. (2000) Caught in a trap? Wage mobility in Great Britain: 19751994. Economica, 67(268), 477-97.

Hartog, J., Pereira, P.T. And Vieira, J.A.C. (2001) Changing returns to education in Portugal during the 1980s and early 90s: OLS and quantile regression estimators. Applied Economics, 33, 1021-1037.

Hofer, H. And Weber, A. (2002) Wage mobility in Austria 1986-1996. Labour Economics, 9, 563-577.

Machin, S. (1998) Recent shifts in wage inequality and the wage returns to education in Britain. National Institute Economic Review, 166, 87-96. 
OECD [Organisation for Economic Co-operation and Development]

(1997) Earnings mobility: taking a longer-run view. In his Employment Outlook, July 199\%. Paris, OECD, 27-61.

OECD [Organisation for Economic Co-operation and Development]

(1992) OECD Economic Surveys, Portugal, 1991/92. Paris, OECD.

Portugal, Ministério do Trabalho e da Segurança Social (1986 to 1999). Quadros de Pessoal. Data in magnetic media.

Shorrocks, A. (1978) Income inequality and income mobility. Journal of Economic Theory, 19(2), 376-393.

\section{Appendix: Panel of workers}

\section{Merging data across years}

The following procedures have been implemented to prepare the worker level data to be merged across years.

Selection of valid worker identification codes: The worker identification code is based on a transformation of the Social Security number and, after contacts with the National Social Security Office, codes made up of 6 to 10 digits were considered for analysis and subsequent data checks. This restriction led to dropping an average 9.1 percent of the observations in the original yearly data sets.

Handling of duplicate worker identification codes in a given year: Workers whose code was unique or duplicate just once, corresponding in fact to the same worker (same gender, date of birth and schooling level) reported working for two different companies, were kept for analysis. This restriction led to dropping on average each year from the original data sets: 0.4 percent of the observations, because the worker code was duplicated more than once; 3.1 percent of the observations because the worker code, though duplicate just once, did not correspond to the same worker (different gender, age or schooling); 0.2 percent of the observations because they corresponded to the same worker being mistakenly reported twice by the same company. 
After the data checks on the worker identification code, on average 87 percent of the original yearly data sets have been kept for analysis, yielding an initial panel of 5,537,232 workers and 25,134,881 observations worker-year.

\section{Checks on the consistency of data for each worker across years}

Inconsistencies were identified if the worker gender or date of birth was reported changing, or if the highest schooling level achieved was reported decreasing over time. The following procedures were implemented to correct these problems.

Correction of missing values when reported data for the rest of the periods was absolutely consistent: Whenever the gender, age or education of a worker was reported consistently but missing in some year(s), it was straightforward to assign the reported value to the missing observation. ${ }^{11}$ These corrections affected 0 percent $^{12}, 2.2$ percent and 1.6 percent of the observations in the initial panel, respectively for gender, age and schooling.

Correction of inconsistent data on gender, birth date or schooling across years: A different problem arised when the information was reported inconsistently across years. In that case, the information reported over half the times has been taken as the correct one. ${ }^{13}$ Inconsistent values on gender were replaced, after checking that the date of birth in the observation to be corrected was the same as the most reported date of birth for that worker. A similar procedure was followed for the birth date and education, replacing inconsistent values with that reported over half the times. According to this procedure, 0.8 percent, 3 percent and 5.7 percent of the observations in the initial panel have been corrected, respectively for gender, birth date and education. Workers with inconsistent data after the introduction of the previous corrections were dropped. Note that the whole information on the worker was dropped, whichever the incorrect number of observations identified: for gender, 2.3 percent of the observations and 2.1 percent of the workers in the

\footnotetext{
${ }^{11}$ If schooling was consistently reported (possibly increasing over time) and the values it achieved before and after a missing were the same, the missing value was corrected; similarly, missings in the initial/final period(s) were extrapolated from the earliest/latest reported value.

${ }^{12}$ Two observations.

${ }^{13}$ Note that this requirement is more demanding than just considering the modal value as the accurate one.
} 
initial panel; for the birth date, 1.4 percent and 1.8 percent, respectively; and for education, 4.5 percent and 3.5 percent, respectively.

Dropping workers with remaining missing data on gender, age or schooling: Workers with missing data after the introduction of the previous corrections were dropped. The share of observations dropped due to missing age or schooling was, respectively, 0.6 percent and 1.9 percent of the initial panel, corresponding to 3 percent and 2.2 percent of the workers.

The checked panel included 22,444,601 observations worker-year and 4,882,908 workers, having therefore kept 89 percent and 88 percent of the initial panel, respectively.

\section{Appendix: Additional tables}

\begin{tabular}{|r||c|c|c|c|c|c|c|c|c|c|c|c|}
\hline \multicolumn{1}{|c||}{} & \multicolumn{10}{c|}{ State in 92 } \\
\hline State in 89 & out db* & miss w* & 1 & 2 & 3 & 4 & 5 & 6 & 7 & 8 & 9 & 10 \\
\hline out db* $^{*}$ & 0.0 & 14.7 & 12.7 & 10.8 & 9.9 & 9.1 & 7.9 & 7.2 & 6.1 & 5.5 & 7.8 & 8.4 \\
miss w & 46.7 & 33.2 & 2.1 & 1.8 & 1.8 & 1.9 & 1.8 & 1.8 & 2.6 & 2.5 & 1.7 & 2.1 \\
1 & 46.6 & 4.5 & 23.0 & 11.3 & 5.4 & 3.2 & 2.2 & 1.5 & 0.9 & 0.6 & 0.3 & 0.6 \\
2 & 41.5 & 3.8 & 9.3 & 18.4 & 11.4 & 6.5 & 3.9 & 2.4 & 1.3 & 0.7 & 0.4 & 0.5 \\
3 & 40.2 & 3.9 & 3.3 & 11.0 & 15.8 & 11.6 & 6.4 & 3.7 & 2.0 & 1.1 & 0.6 & 0.5 \\
4 & 37.7 & 3.9 & 1.8 & 4.3 & 12.0 & 16.3 & 11.6 & 6.4 & 3.2 & 1.5 & 0.7 & 0.6 \\
5 & 34.5 & 4.0 & 1.3 & 2.4 & 5.7 & 12.7 & 18.5 & 11.4 & 5.4 & 2.3 & 1.2 & 0.7 \\
6 & 31.6 & 4.1 & 0.8 & 1.3 & 2.5 & 5.2 & 14.8 & 20.8 & 11.7 & 4.7 & 1.6 & 0.9 \\
7 & 27.6 & 3.9 & 0.5 & 0.7 & 1.2 & 1.9 & 4.6 & 16.6 & 25.2 & 12.6 & 3.7 & 1.5 \\
8 & 24.8 & 3.8 & 0.4 & 0.4 & 0.7 & 0.9 & 1.5 & 3.8 & 18.8 & 31.5 & 10.9 & 2.5 \\
9 & 28.2 & 4.0 & 0.3 & 0.3 & 0.4 & 0.5 & 0.8 & 1.4 & 3.7 & 18.2 & 32.7 & 9.7 \\
10 & 31.0 & 4.5 & 0.4 & 0.3 & 0.3 & 0.5 & 0.5 & 0.6 & 1.0 & 2.6 & 13.7 & 44.7 \\
\hline
\end{tabular}

Table 6: Three-Year transition matrix, males, Portugal, 1989-92.

Source: Computations based on Portugal, MTSS (1989-1992). Notes: $\left(^{*}\right)$ out db - out of the database; miss $\mathrm{w}$ - missing wage (workers who are not wage-earners, but instead owners of the company, unpaid family members or members of cooperatives). 


\begin{tabular}{|r||c|c|c|c|c|c|c|c|c|c|c|c|}
\hline \multicolumn{1}{|c||}{} & \multicolumn{10}{|c|}{ State in 92 } \\
\hline State in 89 & out db* & miss w* & 1 & 2 & 3 & 4 & 5 & 6 & 7 & 8 & 9 & 10 \\
\hline out db* $^{*}$ & 0.0 & 12.7 & 12.5 & 10.1 & 9.2 & 8.7 & 8.4 & 8.4 & 7.9 & 7.5 & 6.5 & 8.0 \\
miss w* & 49.8 & 24.4 & 2.5 & 2.4 & 2.8 & 2.8 & 2.8 & 2.7 & 3.0 & 2.4 & 2.0 & 2.5 \\
1 & 48.0 & 6.0 & 16.6 & 9.0 & 6.9 & 4.2 & 3.4 & 2.5 & 1.6 & 0.9 & 0.4 & 0.5 \\
2 & 42.5 & 5.8 & 7.7 & 11.8 & 10.9 & 8.4 & 5.8 & 3.4 & 1.9 & 1.1 & 0.5 & 0.5 \\
3 & 35.8 & 6.5 & 3.0 & 15.5 & 11.9 & 14.4 & 6.3 & 3.3 & 1.6 & 0.8 & 0.3 & 0.5 \\
4 & 35.7 & 6.3 & 2.7 & 6.7 & 12.6 & 14.3 & 11.5 & 5.6 & 2.5 & 1.1 & 0.6 & 0.5 \\
5 & 35.2 & 6.9 & 1.8 & 3.2 & 8.6 & 10.2 & 15.3 & 10.7 & 4.9 & 2.1 & 0.7 & 0.5 \\
6 & 35.5 & 5.8 & 1.2 & 2.0 & 2.8 & 4.7 & 12.2 & 17.3 & 12.0 & 4.5 & 1.4 & 0.7 \\
7 & 34.0 & 5.5 & 0.8 & 0.7 & 1.0 & 1.3 & 4.0 & 13.5 & 22.5 & 12.4 & 3.3 & 1.1 \\
8 & 32.7 & 5.4 & 0.5 & 0.3 & 0.3 & 0.5 & 0.9 & 3.2 & 14.0 & 29.2 & 10.9 & 2.1 \\
9 & 29.1 & 4.6 & 0.3 & 0.2 & 0.3 & 0.5 & 0.6 & 0.7 & 2.0 & 13.3 & 40.7 & 7.9 \\
10 & 28.6 & 3.7 & 0.3 & 0.2 & 0.2 & 0.2 & 0.3 & 0.3 & 0.5 & 1.4 & 15.2 & 49.3 \\
\hline
\end{tabular}

Table 7: Three-year transition matrix, females, Portugal, 1989-92.

Source: Computations based on Portugal, MTSS (1989-1992). Notes: $\left(^{*}\right)$ out db - out of the database; miss w - missing wage (workers who are not wage-earners, but instead owners of the company, unpaid family members or members of cooperatives).

\begin{tabular}{|r||c|c|c|c|c|c|c|c|c|c|c|c|}
\hline \multicolumn{1}{|c||}{} & \multicolumn{10}{|c|}{ State in 92} \\
\hline State in 87 & out db* & miss w* & 1 & 2 & 3 & 4 & 5 & 6 & 7 & 8 & 9 & 10 \\
\hline out db $^{*}$ & 0.0 & 14.4 & 11.8 & 10.4 & 9.7 & 9.0 & 8.0 & 7.3 & 6.7 & 7.0 & 7.7 & 8.1 \\
miss w* $^{*}$ & 57.2 & 24.7 & 1.9 & 1.5 & 1.6 & 1.8 & 1.7 & 1.7 & 1.7 & 1.9 & 1.9 & 2.4 \\
1 & 53.5 & 4.4 & 14.9 & 9.5 & 5.5 & 4.0 & 2.9 & 2.1 & 1.3 & 0.9 & 0.5 & 0.6 \\
2 & 48.7 & 3.9 & 7.1 & 12.6 & 9.0 & 6.8 & 4.8 & 3.2 & 1.8 & 1.0 & 0.6 & 0.6 \\
3 & 47.0 & 3.7 & 3.0 & 8.8 & 11.2 & 9.4 & 6.9 & 4.6 & 2.7 & 1.5 & 0.7 & 0.7 \\
4 & 45.1 & 3.9 & 1.6 & 4.2 & 9.3 & 11.1 & 9.8 & 7.0 & 4.1 & 2.1 & 1.0 & 0.7 \\
5 & 43.3 & 3.8 & 1.1 & 2.3 & 5.8 & 10.0 & 11.9 & 10.3 & 6.3 & 3.1 & 1.4 & 0.9 \\
6 & 39.5 & 4.4 & 1.0 & 1.6 & 2.5 & 5.6 & 13.1 & 13.5 & 9.9 & 5.2 & 2.4 & 1.2 \\
7 & 36.9 & 4.4 & 0.6 & 0.8 & 1.2 & 2.1 & 5.7 & 15.0 & 16.6 & 10.6 & 4.2 & 2.0 \\
8 & 33.5 & 4.4 & 0.4 & 0.4 & 0.6 & 0.9 & 1.5 & 5.4 & 19.5 & 20.6 & 9.6 & 3.2 \\
9 & 35.6 & 4.3 & 0.3 & 0.3 & 0.4 & 0.5 & 0.6 & 1.2 & 4.2 & 18.3 & 25.7 & 8.7 \\
10 & 39.0 & 4.8 & 0.3 & 0.3 & 0.2 & 0.3 & 0.3 & 0.4 & 0.8 & 1.8 & 14.0 & 37.9 \\
\hline
\end{tabular}

Table 8: Five-year transition matrix, males, Portugal, 1987-92.

Source: Computations based on Portugal, MTSS (1987-1992). Notes: $\left.{ }^{*}\right)$ out db - out of the database; miss w - missing wage (workers who are not wage-earners, but instead owners of the company, unpaid family members or members of cooperatives). 


\begin{tabular}{|r||c|c|c|c|c|c|c|c|c|c|c|c|}
\hline \multicolumn{1}{|c||}{} & \multicolumn{10}{|c|}{ State in 92 } \\
\hline State in 87 & out db* & miss w* & 1 & 2 & 3 & 4 & 5 & 6 & 7 & 8 & 9 & 10 \\
\hline out db* $^{*}$ & 0.0 & 12.5 & 11.4 & 9.8 & 9.2 & 8.7 & 8.3 & 8.5 & 8.0 & 7.5 & 7.7 & 8.3 \\
miss w $^{*}$ & 58.5 & 16.8 & 2.1 & 2.0 & 2.2 & 2.4 & 2.6 & 2.8 & 2.7 & 2.6 & 2.7 & 2.6 \\
1 & 55.9 & 5.6 & 10.5 & 7.3 & 6.0 & 4.7 & 3.5 & 2.6 & 1.9 & 1.2 & 0.5 & 0.5 \\
2 & 50.5 & 5.2 & 5.4 & 8.4 & 8.7 & 7.0 & 6.0 & 4.0 & 2.4 & 1.4 & 0.6 & 0.5 \\
3 & 43.0 & 6.5 & 2.5 & 12.5 & 9.6 & 12.2 & 6.1 & 3.5 & 2.1 & 1.0 & 0.5 & 0.5 \\
4 & 43.8 & 6.3 & 2.4 & 5.6 & 10.3 & 11.2 & 9.8 & 5.3 & 2.9 & 1.4 & 0.7 & 0.4 \\
5 & 40.5 & 7.2 & 1.7 & 3.4 & 7.6 & 9.0 & 13.3 & 8.7 & 4.9 & 2.3 & 1.0 & 0.6 \\
6 & 42.5 & 5.7 & 1.1 & 1.9 & 2.5 & 5.0 & 9.8 & 13.3 & 10.4 & 5.2 & 1.8 & 0.8 \\
7 & 41.7 & 5.4 & 0.8 & 0.8 & 1.1 & 1.4 & 4.4 & 10.9 & 16.4 & 11.6 & 4.2 & 1.4 \\
8 & 40.1 & 5.4 & 0.5 & 0.4 & 0.5 & 0.5 & 1.1 & 3.5 & 13.2 & 22.2 & 10.2 & 2.5 \\
9 & 38.8 & 5.1 & 0.4 & 0.3 & 0.2 & 0.3 & 0.5 & 0.9 & 3.0 & 15.2 & 27.9 & 7.5 \\
10 & 37.5 & 4.1 & 0.3 & 0.1 & 0.2 & 0.3 & 0.4 & 0.5 & 0.6 & 1.5 & 13.5 & 41.2 \\
\hline
\end{tabular}

Table 9: Five-year transition matrix, Females, Portugal, 1987-92.

Source: Computations based on Portugal, MTSS (1987-1992). Notes: $\left.{ }^{*}\right)$ out db - out of the database; miss w - missing wage (workers who are not wage-earners, but instead owners of the company, unpaid family members or members of cooperatives). 